\title{
LAS MONARQUÍAS COMPUESTAS EN LA ÉPOCA MODERNA: CONCEPTO Y EJEMPLOS
}

\author{
The Early Modern composite monarchies: Concept and examples
}

\author{
Matthias Gloël *
}

\begin{abstract}
RESUMEN
Este estudio pretende exponer, por un lado las características fundamentales del concepto de la "monarquía compuesta" en la historia política de la época moderna. Se describen además los diferentes tipos de formar tal monarquía y qué problemas conllevaba una estructura compuesta en dicha época. Por otro lado, son tratados cuatro ejemplos de monarquías compuestas de toda Europa. El primero es el de Escandinavia con la unión de Kalmar, seguida por la corona sueca y la unión danés-noruega. El segundo es el caso de Polonia y Lituania, unión dinástica en el este del continente. El tercero es la monarquía británica, compuesta por los reinos de Inglaterra, Escocia e Irlanda. El cuarto y último es la monarquía hispánica, una vasta monarquía con diversos territorios en varias partes europeas. Al final se valorarán los puntos en común y las diferencias de los cuatro casos ilustrados. Se verá la validez del concepto a nivel europeo, aunque se advierte también no abarca todos lo reinos europeos de la época moderna y que además es discutible su validez acerca de los territorios extra-europeos de estas monarquías.

Palabras clave: Época Moderna, monarquía compuesta, Escandinavia, Polonia, Gran Bretaña, España.
\end{abstract}

\begin{abstract}
This article studies the basic characteristics of the composite monarchies concept Early Modern European political history. It shows different types of this kind of monarchy and the problems caused by such a structure. In order to do so, four examples of composite monarchies will be treated. The first one is Scandinavia with the Kalmar union, followed by the Swedish crown and the Danish - Norwegian union. The second one is the case of Poland and Lithuania in the east of the continent. The third one is the British monarchy, composed of the kingdoms of England, Scotland and Ireland. Finally comes the Spanish monarchy, a vast monarchy of many territories in different parts of Europe. Finally will be evaluated what the four cases what were sown, have in common and also, where the differences lay. It will be shown the validity of the concept on a European level, although it will also been marked that it does not cover all European kingdoms in Early Modern times. Also will be emphasized that the validity of the concept for the overseas territories of these monarchies.
\end{abstract}

Keywords: Early Modern times, composite monarchies, Scandinavia, Poland, Great Britain, Spain.

* Doctor en historia por la Universidad de Hamburgo, Alemania. Correo electrónico: matthias@gloel.de

Artículo recibido el 27 de agosto de 2013. Aceptado el 15 de noviembre de 2013. 


\section{INTRODUCCIÓN}

Helmut Georg Koenigsberger, Conrad Russell y John Elliott son los tres nombres a los cuales se suele hacer referencia cuando se trata del concepto de la "monarquía compuesta". Muchos, como Jesús Gascón Pérez, le atribuyen a Elliott la definición amplia del concepto aunque admite que no fue el primero en usar ese término ${ }^{1}$. El mismo Elliott se refiere en su artículo A Europe of composite Monarchies, el cual fue la teorización del concepto, a Koenigsberger y Russell cuando usa el término "composite state"2. Efectivamente, Koenigsberger destacó ya en 1975, que la mayoría de los estados en la época moderna eran "composite states, including more than one country under the souvereignty of one ruler" Estos territorios podían estar geográficamente separados como era el caso de las posesiones de los Habsburgo en España, Italia y los Países Bajos o podían estar conectados como en los casos de Inglaterra/Gales y Polonia y Lituania. Generalmente cada uno de estos territorios mantenía sus propias cortes, con lo cual el monarca se solía enfrentar a varios parlamentos en vez de uno solo. Éstos, además, podían ser muy distintos entre sí.

Las afirmaciones de Koenigsberger son usadas por Elliott como punto de partida para su mencionado artículo A Europe of composite monarchies. Elliott añade que la monarquía compuesta no fue un invento de la época moderna, sino que ya existían formaciones de ese tipo durante la Edad Media, como en los casos de Borgońa o la Unión Escandinava de Kalmar. Además, añade, la noción "composite state" no era fija, ya que "some early modern states were clearly more composite than others" ${ }^{4}$. Según las referencias introducidas por el jurista del siglo XVII, Juan de Solórzano Pereira, Elliott distingue entre dos tipos de unión para dos territorios. Una sería la "accessory union", en cuyo caso un reino o una provincia pasa a formar jurídicamente parte de otro, lo cual conlleva las mismas leyes para todos los habitantes. La otra la, al llama igual que Solórzano "aeque principaliter" (igualmente importante). En este caso hay que tratar a los reinos o provincias de forma distinta, dado que cada uno de ellos mantiene sus leyes y privilegios propios 5 . Este segundo tipo concuerda con la definición de Koenigsberger para los "composite states". Para el primer caso Elliott entrega el ejemplo de la Corona de Castilla, y para el segundo, el de la Corona de Aragón o los territorios italianos y de los Países Bajos dentro de la monarquía hispánica.

Conrad Russell, incluso, distingue tres formas de los, como él los llama, "multiple kingdoms", y entrega un ejemplo por cada una con la monarquía británica. Las dos mencionados por Elliott también se encuentran en Russell, con los ejemplos, por un lado, de la unión de Inglaterra con Gales y, por otro lado, la de Inglaterra con Escocia, cuya unión compara con la de Castilla y Aragón. Para la unión de Inglaterra con Irlanda, Russell define un tercer tipo que se situaría en medio de los otros dos. Por un lado, Irlanda tenía su propio "Privy Council", parlamento y leyes. Por otro lado, las decisiones de dicho

\footnotetext{
${ }^{1}$ Gascón Pérez, Jesús. Alzar banderas contra su rey. La rebelión aragonesa de 1591 contra Felipe II. Zaragoza: Prensas Universitarias de Zaragoza, ( 2010): 46.

${ }^{2}$ Elliott, John H. "A Europe of composite monarchies", Past and Present 137(Oxford, 1992): 50.

${ }^{3}$ Koenigsberger, Helmut. "Monarchies and parliaments in early modern Europe. Dominium Regale or Dominium Politicum et Regale", Theorie and Society 5/2 (Amsterdam, 1978): 202.

${ }^{4}$ Elliott (1992): 51.

${ }^{5}$ Ibidem, 52-53.

${ }^{6}$ Russell, Conrad. The causes of the English civil war. Oxford: Oxford University Press, Oxford (1990): 40.
} 
parlamento tenían que ser ratificadas en Inglaterra, lo cual implica una clara subordinación de Irlanda a Inglaterra ${ }^{7}$. Elliott no hace esa última distinción, sino en otro artículo define la unión irlandesa como "aeque principaliter" y como contraria a la galesa ${ }^{8}$.

Un estado compuesto se podía formar o extender de varias formas. Una era el principio dinástico, típico de los Habsburgo españoles y también visible en la unión de Inglaterra con Escocia. Otra posibilidad era la extensión por guerra, como muestra el caso de Irlanda con su forma de llegar a la corona británica. Lo mismo ocurrió con el reino de Valencia que se incorporó tras su conquista a la corona de Aragón. También se podía extender un estado compuesto por iniciativa de los súbditos de un territorio, como ocurrió en 1619 cuando los estados de Bohemia ofrecían su corona a Federico V del Palatinado. Lo mismo sucedió durante la revuelta catalana cuando se ofrecía el principado al rey francés Louis XIII.

Se podría pensar que para los monarcas de la época moderna la "accessory union", "perfect union” en el inglés contemporáneo, debía ser la preferible, dado que de esa forma los territorios recién agregados podrían ser asimilados más fácilmente. Pero en realidad, los aparatos administrativos eran aún muy deficientes, por lo que los monarcas dependían de las élites locales, cosa que hacía muy complicado realizar reformas contra la voluntad de los habitantes. El funcionamiento de estas relaciones tenía una gran importancia, porque aunque el rey gobernaba sus territorios, eran esas élites que gobernaban por él a los habitantes. La unión del "aeque principaliter" podía ser por un lado complicada y arriesgada, porque el rey tenía que enfrentarse a varios parlamentos. Sin embargo, estos por otro lado conllevaba la ventaja que en caso de un conflicto en uno de los territorios se podía contar con los recursos de los demás para solucionarlo.

Para Elliott la época moderna se caracteriza por su respeto por estructuras, derechos y privilegios tradicionales, por lo que uniones del tipo "aeque principaliter" encajaban mejor con las necesidades de la época ${ }^{9}$. Por eso, postula Elliott que es necesario investigar la Europa de la época moderna bajo estos planteamientos y no bajo los de los estadios nacionales unificados que solo existirían más tarde. Elliott agrega que sería fácil pensar que los "composite state" solo constituían un estado intermedio camino a los estados unificados. Pero, concluye que no se puede asumir que alrededor de 1600 éstos ya se veían como un objetivo final a alcanzar en el futuro ${ }^{10}$.

Una unión "aeque principaliter" sugiere una unión entre iguales, cosa que formal y efectivamente era así. Sin embargo, en la práctica uno de los miembros solía ser más poderoso que los demás, como Castilla en la monarquía hispánica o Inglaterra en la británica. Esto conllevaba en los demás territorios la pérdida de la presencia continua de su rey y el estatus de sus metrópolis. Durante el siglo XVI, además, crecía la necesidad de una sede fija para la corte, lo cual aumentaba todavía más este problema. Elliott define la ausencia real como "major structural problem", el cual ni siquiera Carlos V con sus continuos viajes por sus dominios era capaz de solucionar ${ }^{11}$. La corte virreinal o la lugartenencia también constituía una solución insuficiente para suplir la corte verdadera. No obstante, afirma Franz Bosbach, se aceptaba sin

\footnotetext{
${ }^{7}$ Ibidem, 40

${ }^{8}$ Elliott, John H. "Catalunya dins d'una europa de monarquies compostes", Pedralbes 13 (Barcelona, 1993): 14.

${ }^{9}$ Elliott (1992): 68.

${ }^{10}$ Ibidem, 51

${ }^{11}$ Elliott (1992): 56.
} 
problemas un monarca o una dinastía que provenía de otro territorio y no se entendían tales relaciones como dependencia o subordinación. Solo en el siglo XIX con el pensamiento de estado nacional se solía interpretar estas relaciones como negativas y con falta de libertades ${ }^{12}$.

El monarca constituía el elemento central que conectaba a todos los territorios, a veces tan diferentes entre ellos. Era rey, príncipe o conde de cada uno de sus territorios, sin poseer un título que representara al conjunto de su monarquía, como por ejemplo rey de España o rey de Britania. También la lealtad de las personas se concentraba fundamentalmente en la persona del rey. Este dinasticismo describe un tipo de lealtad personal hacia el monarca y su muchas veces antigua dinastía y era el elemento central de unión para los territorios de una monarquía compuesta ${ }^{13}$. Para Elliott, era más fácil crear lealtad hacia una persona visible que hacia una comunidad amplia creada por una unión política ${ }^{14}$. Joseph Pérez va más allá e incluso niega que existiera una consciencia de pertenecer a una unidad política mayor. Para él, esa conciencia se limitaba a la así llamada "patria chica" ${ }^{15}$. De la misma manera Javier María Donézar Díez de Ulturrun descarta una conciencia por unidad nacional o política para la época moderna ${ }^{16}$. En cualquier caso, dicha lealtad no sería incompatible como más adelante en los estados nacionales del siglo XIX, de forma que por ejemplo un habitante de la ciudad de Tarragona podía ser tarraconense (ciudad), catalán (reino/principado), aragonés (corona) y español (monarquía), sin que esas lealtades causaran conflictos. Un segundo factor importante para mantener tal unión es el respeto mutuo por los privilegios y compromisos. Ahí es donde, según Elliott, fracasaron de forma fatal tanto Felipe IV en la monarquía hispánica como Charles I en la británica ${ }^{17}$.

La importancia del concepto de la monarquía compuesta radica en el hecho que es una propuesta de análisis muy diferente a la historiografía tradicional, muy marcada por los nacionalismos de los respectivos países. Dicha historiografía veía una ruptura fundamental con la Edad Media al inicio de la época moderna que habría iniciado la época de los estados nacionales. La monarquía compuesta, en cambio, destaca la coninutidad medievista y rechaza los conceptos de "unidad nacional" o "estado nacional".

\section{ESCANDINAVIA}

Más de un caso de una monarquía compuesta da el espacio geográfico de Escandinavia. A lo largo del siglo XIV se formó la unión de Kalmar, basándose en uniones anteriores del mismo siglo. En 1319 Magnus Eriksson heredó la corona noruega cuando solo tenía tres años. Magnus era, al mismo tiempo, descendiente de la familia real sueca. El mismo año la nobleza sueca le ofreció también la corona de Suecia, con lo cual ambos reinos quedaron unidos en la persona del rey. En 1355 Magnus Eriksson dio el reino de Noruega

\footnotetext{
${ }^{12}$ Bosbach, Franz. "Mehrfachherrschaft - eine Organisation frühmoderner Herrschaft". En Michael Kaiser \& Michael Rohrschneider (Eds.), Membra unius capitis. Studien zu Herrschaftsauffassungen und Regierungspraxis in Kurbrandenburg (1640-1688). Berlin: Duncker \& Humblot, (2005): 25.

${ }^{13}$ Torres, Xavier. "A vueltas con el patriotismo. La revuelta catalana contra la Monarquía Hispánica (1640-1659)". En Antonio Álvarez-Ossorio y Bernardo García (Ed.), La monarquía de las naciones. Patria, nación y naturaleza en la monarquía de España. Madrid: Fundación Carlos de Amberes, (2004): 821.

${ }^{14}$ Elliott (1992): 57.

${ }^{15}$ Pérez, Joseph. "Castilla, Cataluña y la monarquía hispánica”, Manuscrits 15 (Barcelona, 1997): 158.

${ }^{16}$ Donézar Díez de Ulturrun, Javier. ”De las naciones-patria y la nación-patria. Del antiguo al nuevo regimen”. En Antonio ÁlvarezOssorio y Bernardo García (Eds.), La monarquía de las naciones. Patria, nación. Madrid: Fundación Carlos de Amberes, (2004): 100. ${ }^{17}$ Elliott (1992): 64.
} 
a su hijo Hakon, el cual se casó posteriormente con la princesa de Dinamarca, entonces el reino más poderoso de Escandinavia. El hijo de los dos, Olav, heredó ambos tronos, con lo cual ahora Noruega se encontró dinásticamente unido a Dinamarca en vez de Suecia. Tras la muerte de Olav, su madre Margarhete asume la regencia en ambos reinos. En 1389 también Suecia le ofrece tras varios conflictos internos la regencia de su reino. Ocho años después, en 1397, finalmente firman nobles y eclesiásticos de los tres reino en Kalmar el tratado de unión, el cual uniría a los tres reinos por más de cien años. A pesar de estar unidos dinásticamente los tres reinos, cada uno mantuvo sus leyes y sus instituciones propias.

A pesar de esta supuesta estabilidad, Harald Gustafsson caracteriza la unión de Kalmar como una unión personal muy débil y un intento fallido de crear un estado escandinavo ${ }^{18}$. Dicha afirmación tiene varias razones. Ninguno de los tres reinos llegó a ratificar el tratado de unión elaborado en Kalmar. Además, a partir de los años 30 del siglo XV los suecos dejaron de reconocer la gran mayoría de los reyes comunes. El país fue gobernado básicamente por consejos o regentes. En 1523 la unión de Kalmar terminó, como consecuencia de intentos centralizadores por parte del rey Christian II que provocaron resistencia en todos los tres reinos ${ }^{19}$.

A continuación se formaron dos nuevas monarquías compuestas, la unión danesa-noruega y la corona sueca. Tras la ruptura de la unión, esta última cayó en manos de la dinastía Vasa que ocuparía el trono sueco durante más de un siglo. Bajo los Vasa Suecia llegó a ser una de las potencias importantes europeas. Durante la segunda mitad del siglo XVI y la primera del XVII, durante la Guerra de los Treinta Años, Suecia conquistó provincias en Finlandia, en el Báltico y en el norte y este de Alemania. La incorporación de éstas se hacía según el principio compuesto de la época moderna: pasaron a formar parte de la corona sueca, sin que llegasen a serlo del reino sueco. También mantuvieron sus leyes y su administración. En las provincias alemanas los monarcas suecos actuaron como señor territorial (Landesherr), dentro del marco del Sacro Imperio.

En cambio, en las conquistas dentro de Escandinavia predomina una política de integración, como Gustafsson ilustra con los ejemplos Gotland, Jämtland y Härjedalen que la corona sueca adquirió en 1645. Estas provincias se incorporaron casi inmediatamente al sistema administrativo, jurídico y político del reino de Suecia ${ }^{20}$. También fueron incorporaciones duraderas, dado que hasta el día de hoy todavía pertenecen al estado sueco. En cambio, las provincias bálticas y la mayoría de las alemanas se perdieron en la así llamada Gran Guerra del Norte que acabó con la derrota de Suecia y que significó el final de su época como potencia europea y de su monarquía compuesta.

También el resto de la unión de Kalmar se reestructuró después de 1523. La nueva monarquía compuesta no sólo abarcaba los reinos de Dinamarca y Noruega, sino también los ducados Schleswig y Holstein. Gustafsson caracteriza esa monarquía como la unión de dos uniones, Dinamarca-Noruega por un lado y Schleswig- Holstein por otro ${ }^{21}$.

La condición noruega en dicha unión no está muy clara. En el juramento del rey Christian III (1536) ya no se considera Noruega como un reino propio, sino como

\footnotetext{
${ }^{18}$ Gustafsson, Harald. "Conglomerates or unitary states? Integration process in early modern Denmark-Norway and Sweden”. En Thomas Fröschl (Ed,). Föderationsmodelle und Unionsstrukturen. Über Staatenverbindungen in der Frühen Neuzeit vom 15. zum 18. Jahrhundert. Viena, Munich: Oldenbourg Verlag München, (1994): 47.

${ }^{19}$ Ibidem, 47.

${ }^{20}$ Ibidem, 52

${ }^{21}$ Ibidem, 59
} 
parte del reino danés ${ }^{22}$. Sverre Bagge llega por esta misma razón a la conclusión de que Noruega perdió su independencia por completo en dicha unión ${ }^{23}$. No obstante, Noruega sí continuó con sus propias leyes e instituciones, por lo que Gustafsson, en cambio, constata que se puede considerar a Noruega como reino propio también después de $1536^{24}$.

La otra parte de la unión eran los dos ducados de Schleswig y Holstein que según el tratado de Ripen de 1460 estaban unidos para siempre ("up ewig ungedeelt"), aunque no obstante, quedaron divididos alguna vez entre diferentes herederos. Pero siempre eran de la misma dinastía y formalmente se gobernaban ambos ducados de forma común, por lo cual efectivamente no se separaron por varios siglos. En cuanto a jurisdicción y administración la integración de los ducados al reino danés era todavía menor que la noruega.

El componente más fuerte de esta monarquía compuesta era el reino danés, donde también habitualmente se encontraba presente el monarca. En Noruega y en los ducados, en cambio, había gobernadores del rey. No hubo procesos de integración durante el siglo XVI y la primera parte del XVII. Si las élites locales se mostraban leales a la corona, ésta no se preocupaba mucho de cómo gobernaban a las provincias ${ }^{25}$. Incluso para el siglo XVII el mismo Gustafsson considera que, a pesar de que algunas medidas se pueden interpretar como centralizadoras, el carácter compuesto de la unión no se modifica ${ }^{26}$.

El fin de esa monarquía compuesta solo llegaría durante el siglo XIX. Primero, en 1814 Dinamarca cede Noruega a Suecia, con el que estaría unido nuevamente hasta 1905 cuando Noruega volvería a tener un rey propio. Los ducados de Schleswig y Holstein, en cambio, se perdieron en 1864 tras la guerra perdida contra la alianza de Prusia y Austria.

\section{POLONIA-LITUANIA}

El ejemplo quizás menos complicado, dado que solo había dos territorios implicados, es el de la unión de Polonia con Lituania. Dicha unión se realizó en 1385 a base de un matrimonio de la reina polaca Hedwig con el gran príncipe de Lituania Jagiello. Józef Gierowski afirma que en Polonia había discusiones sobre una posible incorporación del gran principado pero dado que éste era un territorio mucho más grande que Polonia, la única forma de realizar una unión era de forma dinástica ${ }^{27}$.

Como la unión de Kalmar, la unión entre polacos y lituanos era bastante débil y resultaba difícil mantenerla. Ya al principio como reacción a las tendencias incorporatistas por parte de los polacos, los lituanos eligieron con Witold, un primo de Jagiello, un propio líder, pero al final tuvieron que rendirse y acceder a formar parte de la unión compuesta con Polonia. Igualmente, durante el siglo XV la unión siguió siendo poco sólida y los lituanos llegaron a romperla en varias ocasiones.

\footnotetext{
${ }^{22}$ Ibidem, 55.

${ }^{23}$ Bagge, Sverre. "Nationalism in Norway in the Middle Ages", Scandinavian Journal of History 20, (Londres, 1995): 13.

${ }^{24}$ Gustafsson, 55.

${ }^{25}$ Ibidem, 57.

${ }^{26}$ Ibidem, 58.

${ }^{27}$ Gierowski, Jozef A. "Die Union zwischen Polen und Litauen im 16. Jahrhundert und die polnisch - sächsische Union des 17./18. Jahrhunderts”. En Thomas Fröschl (Ed.), Föderationsmodelle und Unionsstrukturen. Über Staatenverbindungen in der Frühen Neuzeit vom 15. zum 18. Jahrbundert. Viena, Munich: Oldenbourg Verlag München, (1994): 64.
} 
Sin embargo, la unión siempre se restablecía y durante el siglo XVI hubo varias reformas que tenían como objetivo dotar a la nobleza lituana con los mismos (o al menos parecidos) derechos que la polaca. Cuando en los ańos 60 del siglo XVI se veía que se acabaría la dinastía reinante, se buscaba una forma de unión más unida, porque una crisis dinástica hubiese llevado también a una crisis en las relaciones entre Polonia y Lituania ${ }^{28}$. Eso llevó a la unión de Lublin de 1569.

El tratado definía que el reino polaco y el gran principado de Lituania se convertían en un cuerpo con una población que sería unido para siempre ${ }^{29}$. Pero igual que el caso de Dinamarca y Noruega era una unión con muchas limitaciones. Se acordó una política exterior común pero se mantuvieron cargos separados en los dos territorios. Tampoco hubo un ejército común, sino éstos también quedaron separados. Ambos además mantuvieron su propia jurisdicción y su administración.

De todas formas, la unión resultó ser duradera y se mantuvo más de 200 años. Su fin llegó como consecuencia de las particiones de Polonia al final del siglo XVIII (1772, 1793 y 1795) que terminaron formalmente la unión compuesta de estos dos territorios. Hasta entonces fue una unión mucho más sólida que la medieval que habían tenido. Hubo grandes éxitos comunes como la conquista de Livonia que pasó a ser un condominio de ambos. Al final solo la intervención exterior por parte de Rusia, Prusia y Austria la llevó a su fin.

\section{LA MONARQUÍA BRITÁNICA}

Varios tipos de uniones se encuentran en la historia de los reinos británicos e Irlanda. Ya en la Edad Media Inglaterra conquistó a Gales en más de una ocasión y en 1301 el rey inglés coronó a su hijo como primer príncipe de Gales. La administración y las leyes del nuevo principado no se modificaron. Solo más en 200 años más tarde, bajo la nueva dinastía de los Tudor que eran de antecedencia galesa, se emplearon cambios profundos. En 1535 y 1542 se hicieron dos actos de integración jurídica (Laws in Wales Acts), cuyo objetivo era crear un solo estado con una sola jurisdicción. Pero no era una fusión entre iguales, sino se aplicó la jurisdicción inglesa a Gales, con lo que éste prácticamente pasó a formar parte de Inglaterra ${ }^{30}$.

Las uniones inglesas con Escocia e Irlanda, en cambio, eran más complicadas. Hasta 1541 Irlanda ni siquiera era un reino, sino un seńorío (lordship), creado como una posesión papal después de la invasión normanda en 1177. El rey de Inglaterra al mismo tiempo era el señor de Irlanda. El objetivo principal de la creación del reino era justamente evitar posibles pretensiones papales sobre Irlanda ${ }^{31}$. En la práctica no cambiaba mucho para el nuevo reino irlandés. El mismo "Crown of Ireland Act" estableció que Irlanda permanecía "united and knit to the imperial crown of the realm of England"32. Por lo tanto, parecido a lo visto en el caso sueco, Irlanda pertenecía a la corona inglesa pero no al reino inglés. Por un lado también

\footnotetext{
${ }^{28}$ Ibidem, 68.

${ }^{29}$ Ibidem, 69.

${ }^{30}$ Russell, p. 40.

${ }^{31}$ Asch, Ronald. "Die Stuart - Monarchie als composite monarchy: Supranationale Staatsbildung in Großbritannien und Irland im 17. Und frühen 18. Jahrhundert". En Hans J. Becker (Ed,). Zusammengesetzte Staatlichkeit in der Europäischen Verfassungsgeschichte. Berlin: Duncker \& Humblot, (2006): 150.

${ }^{32}$ Robertson, John. "Union by incorporation. England, Scotland and Ireland 1603-1801". En Thomas Fröschl (Ed.), Föderationsmodelle und Unionsstrukturen. Über Staatenverbindungen in der Frühen Neuzeit vom 15. zum 18. Jahrhundert. Viena, Munich: Oldenbourg Verlag München, (1994): 105.
} 
Irlanda tenía sus propias leyes pero por otro lado todas las leyes hechas por el parlamento irlandés necesitaban ser confirmadas por el consejo inglés.

Distinta era la unión con Escocia la cual se produjo de forma dinástica. En 1603 el rey escocés James VI heredó el trono inglés y se convirtió también en James I de Inglaterra. En este caso el monarca sí era la única conexión entre los reinos, ya que el consejo inglés, diferente al caso irlandés, no tenía ninguna competencia en Escocia que mantuvo toda su legislación y sus leyes propias.

Lo que convierte en poco usual el caso británico, es que el propio James no se quiso conformar con esta unión compuesta entre Inglaterra y Escocia y directamente al haber subido al trono inglés inició discusiones sobre una unión que convirtiese a ingleses y escoceses en miembros de un solo cuerpo político ${ }^{33}$. Dichos intentos fracasaron rotundamente por la negación tanto de los ingleses como de los escoceses. En ambos reinos aún había mucha antipatía hacia el otro ${ }^{34}$. Sobretodo el parlamento inglés se puso en contra, porque temía que dicha iniciativa llegase a formar un nuevo estado que anulara a los derechos y privilegios del parlamento ${ }^{35}$. Esto indica que probablemente hubiese sido una unión entre iguales que habría dado paso a un nuevo reino y no la incorporación de un reino en el otro. James, no obstante, insistió y se proclamó en 1604 como rey de Gran Bretańa, pero sin llevar más adelante la unificación institucional. Ambos reinos se mantuvieron independientes sin ninguna forma de subordinación entre ellos.

Para Asch, el factor que causó más problemas entre los tres reinos, fue el religioso ${ }^{36}$. La reformación había transcurrido de forma distinta en cada uno de ellos. En Inglaterra se promovió a través de la corona como consecuencia de las discordias del rey Henry VIII y el papa. En Escocia, en cambio, se introdujo sin influencia de la corona y en parte incluso en contra de ella. El sistema escocés era presbiteriana, por lo cual las parroquias eran mucho más libres que en el sistema episcopal.

La iglesia irlandesa se parecía más a la inglesa, aunque también tenía su propia profesión de fe que estaba más marcada por el calvinismo. Más problemático en el caso irlandés era, no obstante, que los protestantes en sí solo constituían una minoría. La mayoría de los irlandeses seguía siendo católica y eran solo tolerados sin los mismos derechos que los miembros de la iglesia oficial ${ }^{37}$.

Entre 1651 y 1660, bajo el gobierno de Oliver Cromwell, se creó efectivamente durante un breve período un estado británico con un parlamento común, el Commonwealth of England, Scotland and Ireland. Con la restauración de la monarquía, no obstante, se volvió también al sistema compuesta en una unión dinástica ${ }^{38}$. Pero las tensiones de antes seguían latentes, sobretodo las religiosas, aunque también cada vez más las económicas ${ }^{39}$.

Esta unión puramente dinástica con Escocia terminó en 1707 después de una crisis dinástica. Inglaterra aceptó en 1701 la reina Anne de la casa de Hannover sin consultarlo antes con los escoceses ni irlandeses. Éstos no aceptaron dicha sucesión, lo cual inició

\footnotetext{
${ }^{33}$ Ibidem, 106.

${ }^{34}$ Asch, p. 157.

${ }^{35}$ Ibidem, 157.

${ }^{36}$ Ibidem, 145.

${ }^{37}$ Ibidem, 146.

${ }^{38}$ Robertson, p. 108

${ }^{39}$ Ibidem, 109.
} 
negociaciones sobre una unión más sólida que durarían varios años. En Inglaterra se quería conseguir esta reunión a toda costa y al final el parlamento escocés la aprobó tras haber conseguido las élites escocesas concesiones importantes ${ }^{40}$. Dicha unión no conllevaba una centralización en todos los aspectos. Escocia mantuvo su sistema jurídico y su iglesia presbiteriana. En cambio, los impuestos se pagaban ahora al nuevo estado británico, como también ingleses y escoceses pasaron a servir en el ejército común.

Esta unión de 1707 no incluía a Irlanda que seguía siendo un reino a parte, pero, como dice Asch, dependiente de Inglaterra en un estado semi colonial ${ }^{41}$. Ya había quedado fuera de los planes unionistas de James I (VI de Escocia) en 1606 y ahora nuevamente los ingleses no parecían estar interesados en incorporarlos de misma manera que los escoceses. Las élites irlandeses sí deseaban unirse a la nueva corona británica pero estaban conscientes de que Inglaterra no se lo concedería. Así lo expreso por ejemplo el político irlandés diciendo una unión parecida a la escocesa es "an hapiness we can hardly hope for" ${ }^{\prime 2}$. De esta manera Irlanda no consiguió un comercio libre con Inglaterra que hubiese sido muy ventajoso para la economía irlandesa ${ }^{43}$.

Irlanda tendría que esperar casi un siglo más, hasta 1801 para incorporarse al reino unido. En 1798 los irlandeses católicos se habían sublevado y habían recibido mucha ayuda por parte de Francia. Esa amenaza francesa era la razón principal para los ingleses en promover ahora una incorporación del reino irlandés al que ahora se llamaría Reino Unido de Gran Bretaña e Irlanda ${ }^{44}$. Ahí permaneció hasta 1921 cuando 26 de los 32 counties se independizó e Irlanda quedó dividida en la República de Irlanda e Irlanda del Norte que sigue perteneciendo al Reino Unido.

\section{LA MONARQUÍA HISPÁNICA}

Uno de los ejemplos más emblemáticos para una monarquía compuesta es la monarquía hispánica. El mismo Koenigsberger la caracteriza como la "monarchy par excellence of multiple dominios" ${ }^{35}$. Dicha monarquía tuvo su inicio con el matrimonio de los Reyes Católicos en 1469, el cual unió dinásticamente a dos de las tres coronas ibéricas, la de Castilla y la de Aragón.

Pero dichas dos coronas en sí mismas ya constituían monarquías compuestas, representando los tipos definidos por Elliott. Ambas se formaron durante la Edad Media. La Corona de Castilla tuvo su origen en el principado de Asturias que a lo largo de la así llamada "reconquista" se extendió cada vez más hacia el sur. El centro de poder se traspasó primero a León y más adelante a Castilla. Tras varias separaciones por divisiones entre los príncipes, en 1230 Castilla y León - Asturias permanecieron definitivamente unidos. Hasta 1492 (conquista de Granada) se conquistaron varios reinos más de los moros que se incorporaron también en la corona de Castilla.

En total había ocho reinos (Castilla, León, Toledo, Murcia, Córdoba, Jaén, Sevilla y Granada) con representación en las cortes castellanas y había otros como el de Galicia que no

\footnotetext{
${ }^{40}$ Asch, p. 162.

${ }^{41}$ Ibidem, 155.

${ }^{42}$ Robertson, p. 115.

${ }^{43}$ Ibidem, 115.

${ }^{44}$ Ibidem, 118.

${ }^{45}$ Koenigsberger, 203.
} 
la tenían, a pesar de pertenecer igualmente a dicha corona. Desde 1255 existía un decreto según el cual los reinos de la corona castellana ya no se podían separar ${ }^{46}$. La corona entera se regía por las mismas leyes, por lo que la unión seguía el principio de "accessory union", aunque los reinos conquistados no pasaron a formar parte del reino de Castilla, sino de la corona de Castilla. Pero a pesar de que formalmente seguían siendo reinos a parte, sí se introdujo por completo el sistema judicial y administrativo castellano. La única excepción eran el reino de Navarra que sólo se agregó en 1512, pero que mantuvo sus leyes y sus cortes y las tres provincias vascas Alava, Guipózcoa y Vizcaya que se habían unido bajo las mismas condiciones en diferentes momentos de la Edad Media.

En cambio la corona de Aragón estaba formada según el principio del "aeque principaliter". Tuvo su inicio en 1137 cuando se casó Petronila, la heredera del trono del reino de Aragón, con el futuro Ramon Berenguer IV, conde de Barcelona que reinaba en el principado de Cataluña. En 1231 se conquistó Mallorca y en 1237 Valencia donde se fundaron dos nuevos reinos independientes que se integraron con el mismo principio a la corona de Aragón. Cataluña, Aragón y Valencia tenían también cada uno sus propias cortes. Aunque en tiempos de los Habsburgo se convocaron varias veces al mismo tiempo, no existían cortes para toda la corona, sino en estos casos había tres cortes reunidas al mismo tiempo, pero de forma separada. Al final del siglo XIII y principio del XIV se conquistaron también los reinos de Sicilia y Cerdeńa y ambos pasaron a formar parte de la corona. En 1442 bajo Alfonso V además se incorporó al reino de Nápoles.

Dichas dos coronas se unieron, como ya mencionado, de forma "aeque principaliter" en 1469. En los siguientes 100 años aproximadamente se producirían más incorporaciones, a parte de la ya referida del reino de Navarra. El territorio conquistado en las Américas se incorporó después de la muerte de los reyes católicos en la corona de Castilla. En 1535 y 1542 se crearon entonces los virreinatos de la Nueva España y de Perú que se encontraron vía "accessory union" en dicha corona.

En 1580 Felipe II de Castilla (I de Aragón) heredó el trono portugués y sucedió como Felipe I en el reino de Portugal. Dicho reino se había desprendido como condado del reino de León a finales del siglo XI y se convirtió en un reino independiente en 1143 con la proclamación de su primer rey Afonso Henriques. Como los reinos de la corona de Aragón, Portugal también se unió de forma "aeque principaliter", manteniendo sus leyes y privilegios. Con esta incorporación toda la Península Ibérica se encontraba bajo el cetro de un mismo monarca.

Los monarcas residían mayoritariamente y a partir de Felipe II casi únicamente en la corona de Castilla. Los demás reinos se gobernaban con el envío de virreyes que representaban como un alter ego la persona del rey. Su poder era muy grande teóricamente pero se encontraba con bastantes limitaciones en la práctica causadas por los privilegios e instituciones de cada uno de los reinos ${ }^{47}$. Además estaban los consejos territoriales pero éstos tampoco eran capaz de solucionar el problema de la ausencia real ${ }^{48}$.

\footnotetext{
${ }^{46}$ Schmidt, Peer. "Die Reiche der spanischen Krone. Konflikte um die Reichseinheit in der frühneuzeitlichen spanischen Monarchie". En Hans J. Becker (Ed.), Zusammengesetzte Staatlichkeit in der Europäischen Verfassungsgeschichte. Berlin: Duncker \& Humblot, (2006): 173.

${ }^{47}$ Hernando Sánchez, Carlos José. "Estar en nuestro lugar, representando nuestra propia persona. El gobierno virreinal en Italia y la Corona de Aragón bajo Felipe II”. En Emest Belenguer Cebrià (Ed.), Felipe II y el Mediterráneo. La monarquía y los reinos (I). Madrid: Sociedad Estatal para la Conmemoración de los Centenarios de Felipe II y Carlos V, (1999): 221-222. ${ }^{48}$ Cardim, Pedro. "La jornada de Portugal y las Cortes de 1619”. En José Martínez Millán y Maria Antonietta Visceglia (Ed.), La monarquia de Felipe III. Los reinos. Volumen IV. Madrid: Fundación Mapfre, (1999): 946.
} 
Castilla sin duda era el centro y núcleo de poder de la monarquía. Las élites castellanas dominaban las redes del poder y ocupaban la gran mayoría de los cargos importantes como de los virreyes y obispos. Los nobles de los demás reinos, en cambio, estaban marginados y sin esperanza de ocupar algún cargo importante. Los intereses de dichos reinos solo se toleraban si no iban en contra de los de la monarquía ${ }^{49}$. Otro indicio de la importancia decreciente de los reinos periféricos es el hecho de que sus cortes se convocaron cada vez menos, hasta que Felipe III sólo lo hizo una vez en todo su reinado (1598 -1621).

Bajo Felipe IV y su valido Olivares la monarquía ya no podía continuar ignorando estos reinos y sus posibilidades económicas. Los gastos de la corona eran muy altos y necesitaba recaudar dinero y soldados en la corona de Aragón y en Portugal. El problema eran los privilegios de dichos reinos. Mientras en Castilla el rey tenía toda la potestad sobre el uso de los fondos aprobados en cortes, en los otros reinos las cortes no solo tenían que aprobar el dinero, sino también influían en el uso. En la corona de Aragón había un fuero que prohibía usar dinero de la corona de Aragón para asuntos ajenos de los propios reinos.

Por todo ello, Olivares quería reformar la monarquía y deshacerse de las desventajas que conllevaban las uniones "aeque principaliter" para la corona. En su famoso memorial le aconseja al rey:

Tenga V. Maj. por el negocio más importante de su Monarquía el hacerse rey de España; quiero decir, señor, que no se contente V. Maj. con ser rey de Portugal, de Aragón, de Valencia, conde de Barcelona, sino que trabaje y piense con consejo maduro y secreto por reducir estos reinos de que se compone España al estilo y leyes de Castilla, sin ninguna diferencia ${ }^{50}$.

Olivares quería introducir las leyes y la administración castellanas en los otros reinos, aunque no precisamente porque fuesen castellanas, sino seguramente porque la autoridad real en este reino era más alta, por lo que le convenía a la monarquía tener la misma en los demás reinos también.

Pero los reinos periféricos no estaban muy dispuestos a sacrificar sus privilegios y entre otras razones la presión fiscal llevó a dos de ellos a sublevarse contra la monarquía. Cataluña se levantó en verano de 1640, primero solo contra el gobierno ("Viva el rey, abajo el mal gobierno" era el lema inicial de la revuelta) pero a finales de 1641 dejaron de reconocer a Felipe IV (III en la corona de Aragón) como conde de Barcelona, dándole el título al rey francés Louis XIII. Los portugueses, en cambio, que se rebelaron a finales de 1640, proclamaron con João IV directamente otro rey, descendiente de la dinastía de Avis que había quedado extinta en 1578.

La monarquía empleó muchos años de guerra intentando recuperar ambos territorios, pero la escisión portuguesa resultó ser definitiva. Cataluña, en cambio volvió a reconocer Felipe IV en 1652 y éste les volvió a jurar sus privilegios, por lo que el retorno de Cataluña a la monarquía se produjo también de forma "aeque principaliter". Esta monarquía compuesta solo se deshizo varias décadas después tras la guerra de sucesión de

\footnotetext{
${ }^{49}$ Echevarría, Miguel Ángel. "Flandes en la Monarquía Hispánica”. En Conrad Russell (Coord.), Las monarquías del antiguo régimen, ¿monarquias compuestas? Madrid: Editorial Complutense, (1996): 114.

${ }^{50}$ Elliott, John y de la Peña, José (Eds.), Memoriales y cartas del Conde Duque de Olivares. Tomo I. Política Interior: 1621 a 1627. Madrid: Ediciones Alfaguara, (1978): 96.
} 
1701 a 1714. Como consecuencia de su apoyo al archiduque de Austria en la lucha por el trono el nuevo rey Felipe V derogó con el Decreto de la Nueva Planta todas las instituciones y leyes de los reinos de la corona de Aragón. El País Vasco y Navarra mantuvieron sus fueros todavía más de un siglo hasta las guerras carlistas y el triunfo final del liberalismo.

\section{CONCLUSIONES}

Con los cuatro ejemplos ilustrados se pudo apreciar que el concepto de la monarquía compuesta es válida para la Europa de la época moderna. No solo se evidenció en varias monarquías de dicha época, sino que también se ven en partes muy distintas del continente. Además se ve en muchos casos que la forma compuesta no es una señal de debilidad como se quiso interpretar en los siglos XIX y XX, sino más bien resultó ser un factor estabilidad. En cambio, en varios casos los intentos de acabar con dicha estructura resultó ser un peligro para la estabilidad e integridad de las monarquías.

Las monarquías compuestas por varios territorios mostraban los dos tipos de unión definidos por Elliott, excepto el caso de monarquía formada por la corona danesa, donde todos los territorios (Dinamarca, Noruega, Schleswig y Holstein) estaban unidos de forma "aeque principaliter". En el caso de Suecia y la monarquía británica es el miembro más fuerte (Suecia e Inglaterra) que también anexiona territorios de tipo "accessory union". En caso del reino de Suecia son varios territorios escandinavos y en el de Inglaterra el principado de Gales. En cambio, las uniones de Suecia con los territorios alemanes y bálticos y la inglesa con Escocia y hasta cierto punto con Irlanda se hicieron según el principio de "aeque principaliter". Un caso más complejo aún es la monarquía hispánica que inicialmente se compuso de dos coronas enteras, ya compuestas de varias territorios. Por un lado, la corona de Castilla, en la cual todos los territorios se habían ido agregando de forma "accessory union" y por otro lado, la de Aragón, en la cual cada uno de los miembros se había unido de forma "aeque principaliter".

En todos los casos, salvo el de Polonia y Lituania, cuya unión terminó por intervención exterior, se tuvo que tratar el tema de la centralización y uniformización en algún momento. En Escandinavia la unión de Kalmar se rompe tras las iniciativas centralizadoras por parte de la corona. En las dos uniones que resultaron de ella, el tema se trató con mucho cuidado y hubo pocos intentos serios, cosa que quizás contribuyó a que llegasen a existir tanto tiempo. En la monarquía hispánica los reinos periféricos intentaron resistir cualquier intento de la monarquía, ya que para ellos centralización implicaba perder privilegios y derechos frente a la corona. Distinto es el caso británico. Tanto escoceses como ingleses se oponen a una uniformización, ya que ambos piensan que conllevaría una pérdida de derechos frente al rey. Diferente es el caso irlandés. Un siglo después sí tuvieron éxito las reformas centralizadoras. Las élites inglesas se aseguraron sus privilegios parlamentarias y las escocesas también negociaron varias ventajas para antes de votar el acuerdo. Los irlandeses, en cambio, sí veían desde siempre con buenos ojos tener las mismas leyes que Inglaterra, porque para ellos dicha igualdad hubiese supuesto más ventajas que pérdidas. Ahí es la monarquía que los excluye de todo proyecto centralizadora, tanto en 1603 como en 1707. 
Se ve que aunque la formación de todas estas uniones es similar y se puede aplicar el mismo concepto (el de la monarquía compuesta) a ellas, los procesos, el desarrollo y las relaciones entre sus miembros y con la monarquía resultan ser en cada caso distintos. La demostrada validez del concepto no significa que éste sea apto para todos los reinos o monarquías europeos de dicha época. Sobre todo el caso de Francia, el cual era uno de los reinos más importantes de dicha época, está muy discutido si se trata de una formación compuesta o no. Por un lado, Russell rechaza la posibilidad de aplicar el concepto de la "monarquía compuesta" al reino francés, ya que únicamente sería aplicable al caso del Bearne, pero no al resto de Francia ${ }^{51}$. Rogelio Pérez Bustamante, en cambio, afirma que no se puede definir a la Francia moderna como una monarquía centralista y unificada, tal como lo hacía la historiografía tradicional ${ }^{52}$. Se remite a territorios como la Bretaña, la Normandía y la Gascuńa que sí mostraban diferencias regionales y los títulos distintivos que llevaba el monarca (Delfín en el Delfinado, Conde en Provenza) ${ }^{53}$.

También queda abierta la posible validez de dicho concepto para los territorios fuera de Europa, al menos para los casos de la monarquía hispánica y británica. Ambas poseían territorios fuera de Europa que sin duda permanecían a la monarquía pero habría que analizar más a fondo si se les puede considerar partes compuestas de la misma. El mismo Elliott parece que limita de cierta forma la noción de "monarquía compuesta" a los reinos europeos, dado que cuando se centra en los territorios americanos suele hablar de "imperio" en vez de "monarquía compuesta" ${ }^{4}$. Las Américas eran una parte importante y económicamente esencial de dichas dos monarquías, sobre todo en caso de la hispánica. Por lo tanto sería de gran importancia investigar el verdadero encaje de dichos territorios en la monarquía hispánica y británica.

\section{REFERENCIAS}

Asch, Ronald. "Die Stuart - Monarchie als composite monarchy: Supranationale Staatsbildung in Großbritannien und Irland im 17. Und frühen 18. Jahrhundert". En Hans J. Becker (Ed,). Zusammengesetzte Staatlichkeit in der Europäischen Verfassungsgeschichte. Berlin: Duncker \& Humblot, (2006): 141-170.

Bagge, Sverre. "Nationalism in Norway in the Middle Ages", Scandinavian Journal of History 20 (Londres, 1995): 1-18.

Bosbach, Franz. "Mehrfachherrschaft - eine Organisation frühmoderner Herrschaft". En Michael Kaiser \& Michael Rohrschneider (Eds.), Membra unius capitis. Studien zu Herrschaftsauffassungen und Regierungspraxis in Kurbrandenburg (1640-1688). Berlin: Duncker \& Humblot, (2005): 19-34.

\footnotetext{
${ }^{51}$ Russell, p. 32.

52 Pérez Bustamante, Rogelio. "La Francia del Antiguo Régimen: vocación uniforme y diversidad jurídica e institucional". En Conrad Russell y José A. Gallego (Eds.), Las monarquías del antiguo régimen, ¿monarquías compuestas? Madrid: Editorial Complutense, (1996): 123.

${ }^{53}$ Ibidem, 123-124.

${ }^{54}$ Elliott, John. Empires oft he Atlantic world: Britain and Spain in America, 1492-1830. New Haven: Yale University Press, 2006; Elliott, John. Imperial Spain 1469-1716. London: Penguin Books, 2002.
} 
Cardim, Pedro. "La jornada de Portugal y las Cortes de 1619”. En José Martínez Millán y Maria Antonietta Visceglia (Ed.), La monarquia de Felipe III. Los reinos. Volumen IV. Madrid: Fundación Mapfre, (1999): 900-946.

Hernando Sánchez, Carlos José. "Estar en nuestro lugar, representando nuestra propia persona. El gobierno virreinal en Italia y la Corona de Aragón bajo Felipe II". En Emest Belenguer Cebrià (Ed.), Felipe II y el Mediterráneo. La monarquía y los reinos (I). Madrid: Sociedad Estatal para la Conmemoración de los Centenarios de Felipe II y Carlos V, (1999): 215-338.

Donézar Díez de Ulturrun, Javier. "De las naciones-patria y la nación-patria. Del antiguo al nuevo regimen". En Antonio Álvarez-Ossorio y Bernardo García (Eds.), La monarquia de las naciones. Patria, nación. Madrid: Fundación Carlos de Amberes, (2004): 93-118.

Echevarría, Miguel Ángel. "Flandes en la Monarquía Hispánica”. En Conrad Russell (Coord.), Las monarquias del antiguo régimen, ¿monarquías compuestas? Madrid: Editorial Complutense, (1996): 113-121.

Elliott, John y de la Peña, José (Eds.), Memoriales y cartas del Conde Duque de Olivares. Tomo I. Politica Interior: 1621 a 1627. Madrid: Ediciones Alfaguara, (1978): 48-71.

"Catalunya dins d'una europa de monarquies compostes", Pedralbes 13

(Barcelona, 1993): 11-23.

Imperial Spain 1469-1716. London: Penguin Books, 2002.

Empires oft he Atlantic world: Britain and Spain in America, 1492-1830. New Haven: Yale University Press, 2006

Gascón Pérez, Jesús. Alzar banderas contra su rey. La rebelión aragonesa de 1591 contra Felipe II. Zaragoza: Prensas Universitarias de Zaragoza, ( 2010).

Gierowski, Jozef A. "Die Union zwischen Polen und Litauen im 16. Jahrhundert und die polnisch - sächsische Union des 17./18. Jahrhunderts". En Thomas Fröschl (Ed.), Föderationsmodelle und Unionsstrukturen. Über Staatenverbindungen in der Frühen Neuzeit vom 15. zum 18. Jahrhundert. Viena, Munich: Oldenbourg Verlag München, (1994): 63-82.

Gustafsson, Harald. "Conglomerates or unitary states? Integration process in early modern Denmark-Norway and Sweden”. En Thomas Fröschl (Ed,). Föderationsmodelle und Unionsstrukturen. Über Staatenverbindungen in der Frühen Neuzeit vom 15. zum 18. Jahrhundert. Viena, Munich: Oldenbourg Verlag München, (1994): 45-62. 
Koenigsberger, Helmut. "Monarchies and parliaments in early modern Europe. Dominium Regale or Dominium Politicum et Regale", Theorie and Society 5/2 (Amsterdam, 1978): 191-217.

Pérez, Joseph. "Castilla, Cataluña y la monarquía hispánica”, Manuscrits 15 (Barcelona, 1997): 158.

Pérez Bustamante, Rogelio. "La Francia del Antiguo Régimen: vocación uniforme y diversidad jurídica e institucional”. En Conrad Russell y José A. Gallego (Eds.), Las monarquías del antiguo régimen, ¿monarquías compuestas? Madrid: Editorial Complutense, (1996): 123-132.

Robertson, John. "Union by incorporation. England, Scotland and Ireland 16031801”. En Thomas Fröschl (Ed.), Föderationsmodelle und Unionsstrukturen. Über Staatenverbindungen in der Frühen Neuzeit vom 15. zum 18. Jahrhundert. Viena, Munich: Oldenbourg Verlag München, (1994): 104-118.

Schmidt, Peer. "Die Reiche der spanischen Krone. Konflikte um die Reichseinheit in der frühneuzeitlichen spanischen Monarchie”. En Hans J. Becker (Ed.), Zusammengesetzte Staatlichkeit in der Europäischen Verfassungsgeschichte. Berlin: Duncker \& Humblot, (2006): 171-196.

Torres, Xavier. "A vueltas con el patriotismo. La revuelta catalana contra la Monarquía Hispánica (1640-1659)”. En Antonio Álvarez-Ossorio y Bernardo García (Ed.), La monarquía de las naciones. Patria, nación y naturaleza en la monarquia de España. Madrid: Fundación Carlos de Amberes, (2004): 811-844. 